\title{
GRAMÍNEAS E LEGUMINOSAS NA RECUPERAÇÃO DE ÁREAS DEGRADADAS: EFEITO NAS CARACTERÍSTICAS QUÍMICAS DE SOLO(1)
}

\author{
A. C. SANTOS ${ }^{(2)}$, I. F. SILVA(3), J . R. S. LIMA(2), \\ A. P. ANDRADE ${ }^{(3)} \&$ V. R. CAVALCANTE ${ }^{(4)}$
}

\begin{abstract}
RESUMO
Com o objetivo de avaliar a eficiência de duas leguminosas e duas gramíneas na melhoria das características químicas do solo (carbono orgânico, CTC efetiva e potencial e teores de $\mathrm{P}, \mathrm{K}, \mathrm{Na}, \mathrm{Ca}, \mathrm{Mg}, \mathrm{H}+\mathrm{Al}$ e $\mathrm{pH}$ do solo), considerando a profundidade e a posição de coleta das amostras, foi realizado experimento com arranjo fatorial em parcelas subdivididas, utilizadas anteriormente para estudos de perdas de solos por erosão, em um Nitossolo Vermelho eutrófico textura argilosa, localizado no município de Alagoinha (PB). Os tratamentos utilizados constituíram-se de duas leguminosas (feijão guandu - Cajanus cajan L. e si ratro - Macroptili um atropurpureum L.), duas gramíneas (capim-pangola - Digitaria decumbens $L$. e capim-elefante - Penni setum purpureum L.) e parcela desnuda (testemunha), com três repetições. A utilização das legumi nosas e das gramíneas promoveu aumentos nos teores de carbono orgânico total e na capacidade de troca de cátions; promoveu, também, aumento nos teores de potássio, matéria orgânica e magnésio, principalmente na camada superficial. 0 maior acúmulo de liteira foi conseguido com o capim-elefante, sendo este acúmulo maior na posição inferior das parcelas em todos os tratamentos.
\end{abstract}

Termos de indexação: capacidade de troca de cátions, matéria orgânica, características químicas do solo, carbono orgânico.

\footnotetext{
(1) Recebido para publicação em julho de 1999 e aprovado em maio de 2001.

(2) Doutorando em Tecnologias Energéticas e Nucleares, Departamento de Engenharia Nuclear, Universidade Federal de Pernambuco - UFPE. Av. Prof. Luiz Freire 1000, CEP 50730-000 Recife (PE). Bolsista CNPq. E-mail: antclementino@yahoo.com

(3) Professor Adjunto do Departamento de Solos da Universidade Federal da Paraíba - UFPB. Campus III, CEP 58397-000 Areia (PB).

(4) Engenheiro-Agrônomo, INTERPA-PB.
} 


\title{
SUMMARY: GRASS AND LEGUMINOUS SPECIES USED FOR RECOVERING DEGRADED AREAS: EFFECTS ON SOIL CHEMICAL CHARACTERISTICS
}

\begin{abstract}
This work aimed to evaluate the efficiency of two leguminous and two grass species in improving soil chemical characteristics (organic carbon, effective, and potential CEC and available levels of $\mathrm{P}, \mathrm{K}, \mathrm{Ca}, \mathrm{Mg}, \mathrm{H}$ and $\mathrm{pH}$ ) as a function of the depth and position of the sample collection. The experiment design was a split plot in a factorial scheme The plot was previously used for studies of soil losses by erosion, and the soil classified as "Nitossol o Vermel ho E utrófico", loamy texture. Thetreatments consisted of two leguminous species (guandú - Cajanus cajan L. and siratro - Macroptilium antropurpureum L.) and two grasses (elephant grass - Digitaria decumbens L. and elephant grass - Pennisetum purpureum L.), with three replications. The use of the leguminous and grass species increased the total organic carbon level, the exchange cation capacity, and the potassium, organic matter and magnesium levels, mainly in the surface layer. The largest litter accumulation was reached with elephant grass in the lower position of the plots in all treatments.
\end{abstract}

Index terms: grass and leguminous species, soil chemical characteristics.

\section{INTRODUÇÃO}

A rápida degradação do solo sob exploração agrícola no mundo, especialmente nos países tropicais em desenvolvimento, despertou, nas últimas décadas, a preocupação com a qualidade do solo ea sustentabilidade da exploração agrícola (Lal \& Pirce, 1991). Desde então, vários conceitos de qualidade do sol o foram propostos; o melhor deles, porém, define a qualidade do sol o como sendo a sua capacidade em manter a produtividade biológica, a qualidade ambiental e a vida vegetal e animal saudável na face da terra (Doran \& Parkin, 1994).

Para monitorar a qualidade do solo, com vistas em sugerir modificações nos sistemas de manejo utilizados pel os agricultores a tempo de evitar a sua degradação, é necessário definir atributos de solo e do ambiente sensíveis ao manejo e de fácil determinação (Mielniczuk, 1999). Larson \& Pirce (1994) propuseram um conjunto mínimo de variáveis químicas, físicas e biol ógicas, que, acompanhadas ao longo do tempo, são capazes de detectar as alterações da qualidade do solo de acordo com o manejo. O carbono orgânico total (COT) e a matéria orgânica (MO) do solo encontram-se entre essas variáveis. A recuperação do potencial produtivo pode ser obtida com o uso de sistemas de manejo com a utilização de plantas recuperadoras de solo, comoleguminosas, que, aumentando o teor da matéria orgânica, decorrente de seu rápido crescimento, promovem a recuperação das características físicas, químicas e biológicas do solo (Bertoni et al., 1972; Miyasaka, 1984).

Em sol os degradados, os baixos teores de matéria orgânica podem determinar menor disponibilidade de nutrientes para as culturas, resultando numa das principais limitações à produtividade agrícola. A adoção de métodos de preparo (cultivo mínimo e plantio direto), que promovem menor revolvimento do solo, e a adoção de um sistemas de culturas com a inclusão de leguminosas e gramíneas, que contêm mai ores quantidades de nitrogênio na sua biomassa, acarretam, com o tempo, uma melhoria nas características químicas, restrita inicialmente às camadas superficiais (Bayer \& Mielniczuk, 1997a).

A recuperação de áreas degradadas éum processo e, como tal, é composto por várias etapas que devem ser desenvolvidas num conjunto, para obter o resultado final que é restabelecer o seu potencial de produção. Em muitos casos, as áreas declivosas são exploradas sem nenhum controle à erosão pelos produtores. Este trabal ho visa avaliar a eficiência de duas leguminosas e duas gramíneas em mel horar atributos químicos de um Nitossolo Vermelho eutrófico degradado ao longo do declive e em diferentes profundidades do perfil.

\section{MATERIAL E MÉTODOS}

O experimento foi realizado na Estação Experimental da Empresa Estadual de Pesquisa Agropecuária da Paraíba (EMEPA-PB), localizada no município de Alagoinha (PB), em Nitossolo Vermel ho eutrófico.

A área experimental constou de 15 parcelas, com 20 metros de comprimento ecinco metros de largura, com uma declividade de $12 \%$. Esta área foi utilizada por 12 anos consecutivos (1978-1990) em estudo de 
perda de solo por erosão, período em que foram testados diferentes tipos de cultura (milho, al godão, feijão, mandioca, cana-de-açúcar e capim-pangola) e algumas práticas simples de controle de erosão (plantio em nível, faixa de retenção e sulcos em nível). As parcelas experimentais por ocasião da instalação deste experimento apresentavam-se bastante desgastadas pela er osão e baixa fertilidade.

O experimento foi realizado em um arranjofatorial em parcelas subdivididas, com cinco tipos de uso do solo (duas leguminosas, feijão guandu - Cajanus cajan L. esiratro - Macroptilium atropurpureum L.; duas gramíneas -capim-pangola - Digitaria decumbens L . e capim-el efante - Pennisetum purpureum L. e parcela desnuda - testemunha), três posições no relevo (superior, média einferior), cinco profundidades (0-2, 2-4, 4-8, 8-16 e 16-32 cm) e três repetições.

Estes tratamentos foram aplicados durante os anos de 1997 e 1998, e, no mês de setembro de 1998, foram col etadas amostras de sol o para a caracterização química da área em estudonas áreas preestabelecidas; cada amostra foi composta de três amostras simples. O solo foi seco ao ar e passado em peneira com abertura de malha de $2 \mathrm{~mm}$ de diâmetro.

As amostras foram analisadas quanto aos teores decarbono orgânico total - COT (oxidação da matéria orgânica via úmida com dicromato de potássio em mei o sulfúrico, empregando como fonte de energia o aquecimento), $\mathrm{P}$ e K (método Mehlich-1), Ca, Mg e Al trocável (método do $\mathrm{KCl} 1 \mathrm{~mol} \mathrm{~L}^{-1}$ ), $\mathrm{pH}$ em água (relação solo-solução 1:2,5) eacidez potencial $(\mathrm{H}+\mathrm{Al}$ em $\mathrm{pH}$ 7,0) de acordo com EMBRAPA (1997). A capacidade de troca de cátions (CTC) efetiva foi estimada pela soma dos teores de $\mathrm{Ca}, \mathrm{Mg}, \mathrm{K}, \mathrm{Na}$ eAl trocável, enquanto a capaci dade de troca de cátions potencial (CTC em $\mathrm{pH} 7,0$ ), pela soma de $\mathrm{Ca}, \mathrm{Mg}$, $\mathrm{Na}$, K trocável e $\mathrm{H}+\mathrm{Al}$.
Para coleta da liteira sobre o solo, foi utilizado um quadrado de madeira, com as dimensões de $0,50 \times 0,50 \mathrm{~m}$. O procedimento para coleta das amostras consistiu de jogar o quadrado em diferentes posições das parcel as superiore-s, mediana einferior, coletando-se a liteira que ficava no interior deste quadrado. Após a coleta, as amostras foram col ocadas em estufa à temperatura constante $\left(65^{\circ} \mathrm{C}\right)$ para secagem, sendo, posteriormente, pesadas (gramas) e o peso convertido para $\mathrm{kg} \mathrm{ha}^{-1}$.

Os resultados dos atributos químicos foram analisados estatisticamente (análise de variância), considerando o delineamento utilizado e os tratamentos (duas leguminosas, duas gramíneas e a testemunha - sem vegetação), os três pontos de col eta (pel ofato de a área apresentar uma dedividade de $12 \%)$ e as cinco profundidades $(5 \times 3 \times 5)$. A comparação entre as médias dos tratamentos foi realizada pelo teste de Tukey, a 1 e $5 \%$ de probabilidade.

\section{RESULTADOS E DISCUSSÃO}

O uso do sol oe a declividade, de acordo com Woods \& Schuman (1988), ambos podem influenciar as características físicas e químicas do solo. Pelo quadro 1, observa-se que o tipo de cultivo, posição decol eta e profundidadeinfluenciam as características químicas do sol o. Entretanto, as séries de interações destes atributos não foram, em geral, significativas para os elementos analisados.

\section{Manta vegetal (liteira)}

Na figura 1, encontram-se os resultados médios da liteira sobre o solo, referentes às espécies

Quadro 1. Significância dos valores de F, considerando os parâmetros estudados (culturas, posição de coleta e profundidade) sobre a matéria orgânica (MO), pH em $\mathrm{H}_{2} \mathrm{O}, \mathrm{Ca}, \mathrm{Mg}, \mathrm{K}, \mathrm{P}, \mathrm{H}$ + Al, CTC efetiva e CTC potencial

\begin{tabular}{|c|c|c|c|c|c|c|c|c|c|}
\hline \multirow[b]{2}{*}{ Fonte de variação } & \multirow[b]{2}{*}{ pH } & \multirow[b]{2}{*}{ MO } & \multirow[b]{2}{*}{ Ca } & \multirow{2}{*}{ Mg } & \multirow{2}{*}{$\mathbf{K}$} & \multirow[b]{2}{*}{$\mathbf{P}$} & \multirow{2}{*}{$\mathbf{H}+\mathbf{A l}$} & \multicolumn{2}{|c|}{ СTC } \\
\hline & & & & & & & & E fetiva & Potencial \\
\hline & \multicolumn{9}{|c|}{ Efeitos simples } \\
\hline Culturas & ns & $* *$ & ns & $* *$ & ns & ns & ns & $* *$ & $* *$ \\
\hline Posição de coleta & ns & $* *$ & ns & ns & $* *$ & ns & ns & $* *$ & $* *$ \\
\hline \multirow[t]{2}{*}{ Profundidade } & $* *$ & $* *$ & $* *$ & $* *$ & $* *$ & $* *$ & $* *$ & $* *$ & $* *$ \\
\hline & \multicolumn{9}{|c|}{ Interações } \\
\hline Cultura x posição de coleta & ns & ns & ns & ns & $*$ & ns & ns & ns & ns \\
\hline Cultura $\times$ profundidade & ns & ns & ns & ns & $* *$ & ns & ns & $* *$ & ns \\
\hline Posição de coleta $x$ profundidade & ns & ns & ns & ns & ns & ns & $*$ & ns & ns \\
\hline Cultura x posição $x$ profundidade & ns & ns & ns & ns & ns & ns & ns & ns & ns \\
\hline
\end{tabular}

*, ** e ns: Significativos a 0,05 e 0,01 de probabilidade e não-significativo. 
analisadas no decorrer de dois anos, em três posições de cada parcela ao longo do dedive. O capim-el efante foi a espécie que mais depositou liteira sobre o solo, diferenciando-se das demais espécies $(P<0,01)$. O capim-pangola, oguandu eosiratronão diferenciaram entresi $(P>0,05)$. O acúmulo médio deliteira sobre o sol o do capim-el efante foi de 8,93 t ha-1, enquanto o do capim-pangola foi de $3,73 \mathrm{t} \mathrm{ha}^{-1}$, para o guandu de $3,71 \mathrm{t} \mathrm{ha}^{-1}$ edosiratrofoi de $3,07 \mathrm{t} \mathrm{ha}^{-1}$. O capimelefante produziu um acúmul o médi o de liteira sobre o sol o superior em 58,2\% ao do capim-pangola, 58,4\% ao do guandu e $65,6 \%$ ao do siratro.

Em relaçãoàs posições de col eta, a posição inferior apresentou-se com maior acúmulo de liteira depositada sobre o solo em relação às demais. No capimel efante, na posição inferior, oacúmulo médio deliteira sobre o solo foi de 13,40 t ha-1 $^{-1}$, enquanto na posição mediana foi de $8,28 \mathrm{t} \mathrm{ha}^{-1}$ e na posição superior foi de 5,11 t ha-1 ${ }^{-1}$ ou seja, a posi ção inferior produzi u mais $38 \%$ em relação à posição mediana e 61,82\% superior à posição superior. No capim-pangola, na posição inferior, a liteira sobre o solo foi de $4,56 \mathrm{t} \mathrm{ha}^{-1}$, na posição mediana de 3,96 e 2,69 t ha-1 na posição superior, sendo o acúmulo de liteira da posição inferior superior em 13,15\% em relação à posição mediana e 40,96\% em relação à posição superior. 0 guandu apresentou um acúmulo médio de liteira sobre o solo na posição inferior de $4,13 \mathrm{t} \mathrm{ha}^{-1}$, na posição mediana de $3,78 \mathrm{t} \mathrm{ha}{ }^{-1}$ ena posição superior foi de 3,23 t ha-1, ou seja, o acúmulo de liteira na posição inferior foi superior em $8,55 \%$ à posição mediana e $21,89 \%$ à posição superior. O siratro apresentou um acúmul o médi o de liteira sobre o solo na posição de amostragem inferior de 3,94 t ha-1; na posição mediana de 3,28 e 2,00 t ha $^{-1}$ na posição

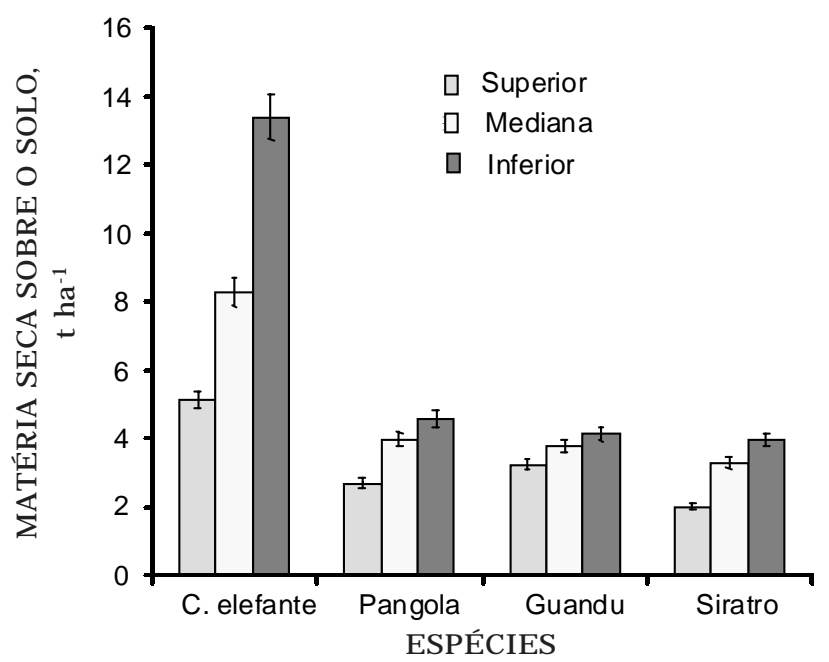

Figura 1. Quantidades de matéria seca sobre o solo depositadas pelas espécies analisadas no decorrer de dois anos, coletadas em três posições de cada parcela ao longo do declive. As barras verticais indicam o desvio-padrão da média. superior, ou seja, a liteira acumulada sobre a superfície do solo na posição inferior foi $16,71 \%$ superior à da posição mediana e 49,17\% superior à da posição superior. Segundo Gonçalves \& Cereta (1999), a quantidade de carbono orgâni co acumulado no sol o depende fundamental mente da quantidade de massa seca produzida pel o sistema de cultura.

\section{Carbono orgânico total (COT)}

No quadro 2, encontram-se os resultados para carbono orgânico total, considerando a profundidade de amostragem, em cada tratamento. Na área descoberta, os teores de COT foram de 12,17, 10,05, $8,57,7,33 \mathrm{~g} \mathrm{dm}^{-3} \mathrm{e} 5,42 \mathrm{mg} \mathrm{dm}^{-3}$, nas camadas de 0 2, 2-4, 4-8, 8-16 e 16-32 cm, respectivamente. Verificaram-se diferenças entre as profundidades em todos os tratamentos. Porém, quando se avaliou a testemunha, em relação às culturas, observou-se que capim-pangola, capim-el efante, siratro e guandu não diferiram entre si, diferindo-se apenas em relação à testemunha ( $P<0,01$ ). Em média, a testemunha apresentou um teor de COT de $8,7 \mathrm{~g} \mathrm{dm}^{-3}$, enquanto o do capim-pangola foi de $9,61 \mathrm{~g} \mathrm{dm}^{-3}, 9,93 \mathrm{~g} \mathrm{dm}^{-3}$ para o capim-el efante, $10,3 \mathrm{~g} \mathrm{dm}^{-3}$ para o siratro e $9,8 \mathrm{~g} \mathrm{dm}^{-3}$ para o guandu.

A utilização dessas culturas na recuperação de áreas degradadas resultou em um incremento nos teores de COT no solo. A ausência de diferença nos teores de COT do sol o entreas famílias leguminosae e gramineae, apesar de apresentarem capacidade diferenciada da adição de material orgânico, indica que ambas podem ser utilizadas na recuperação de áreas degradadas. Bayer \& Mielniczuk (1997a), trabalhando com sistemas de culturas, afirmaram que a ausência de diferença nos teores de COT demonstra a preponderância dos métodos de preparo em relação aos sistemas de cultura quanto à alteração no teor de COT nas condições de solo e clima do experimento.

Em estudo de sol o sob campo nativo, onde não há alteração na vegetação existente, Bayer (1996) afirmou que os teores de COT giravam em torno de um val or estável, encontrando-se os val ores deCOT de 23,59 $\mathrm{g} \mathrm{dm}^{-3}$, na camada de 0-2,5 cm, de 16,70, nas camadas de $2,5-5,0$, ede $12,19 \mathrm{~g} \mathrm{dm}^{-3}$, na camada de $5,0-10,0 \mathrm{~cm}$. Os baixos valores no sol o do presente estudo deveram-se à intensa degradação dos anos anteriores, e a recuperação deve ocorrer a partir de fol has vel has caídas e da atividade radicular.

Segundo Bayer (1996), o efeito dos sistemas de manejo sobre os teores de matéria orgânica ocorre, inicialmente, na camada superficial. Todavia, com o passar do tempo, manifesta-se em camadas mais profundas. Em sua maioria, os estudos sobre o efeito de sistemas de manejo têm comprovado que as modificações nos teores de COT e matéria orgânica são lentas, necessitando de um período de tempo mai or para serem detectadas. Todavia, Testa et al. (1992) comprovaram que o aumento na matéria 
orgânica resultou, após nove anos, num aumento da CTC do solo e numa melhoria das características químicas do solo (diminição da toxidez deAl emaior disponibilidade de nutrientes, principalmentedo N).

Analisando os locais de col eta de sol o em relação à posição (Quadro 3), verificou-se ser a posição da área também um fator limitante ao incremento de COT no solo. Os menores teores ocorreram na posição mediana das parcelas; entretanto, a posição inferior do declive foi a que apresentou os maiores teores de COT $(P<0,01)$. Em média, o teor na posição inferior do declive foi de $10,01 \mathrm{~g} \mathrm{dm}^{-3}$, na posição média de $9,2 \mathrm{~g} \mathrm{dm}^{-3}$ e na posição superior de $9,7 \mathrm{~g} \mathrm{dm}^{-3}$. Com relação às culturas, ambas as famílias foram superiores $(P<0,01)$ à testemunha, embora não diferissem entre si. Essa interação da cultura ea posiçãoéimportante, porque dá uma idéia de qual é o método de manejo de culturas mais adequado a ser adotado.

Esse efeito da posição de amostragem do solo sobre o teor de COT foi resultante de erosão, isso porque a declividade favorece as perdas do material orgânico sobre a superfície, além de favorecer a atuação dos fatores ambientais, como umidade, aeração e até mesmo a temperatura. Segundo Bayer \& Mielniczuk (1997a), o COT é afetado tanto por oxidação como por erosão e está relacionado com a intensidade de revolvimento do solo pela sua influência nos regimes de aeração, umidade e temperatura, ruptura dos agregados, exposição da superfície, fracionamento e incorporação dos resíduos culturais.

Os métodos convencionais de preparo de solo, utilizados em culturas anuais, normal menteprovocam redução acentuada nos teores de COT, resultante do aumento da taxa de decomposição anual de COT e ou redução da taxa de adição anual de COT (Dalal \& Mayer, 1996a,b). Fatores como profundidade e declividade deveriam ser monitorados, porque fornecem informação de como o manejo adotado está atuando na recuperação de sol os degradados, uma vez que a declividade é um fator que favorece as perdas por erosão.

Nos métodos convencionais de preparo do solo para culturas anuais, o teor de COT tende a valores baixos, podendo estar aquém do necessário para manter as condições satisfatórias à produtividade das culturas, pela estreita relação que existe entre

Quadro 2. Teores de carbono orgânico total do solo (COT), considerando a profundidade (0-2, 2-4, 4-8, 8-16 e 16-32 cm), com a utilização de algumas culturas recuperadoras de áreas degradadas

\begin{tabular}{lccccc}
\hline \multirow{2}{*}{ Tratamento } & \multicolumn{5}{c}{ Profundidade $(\mathbf{c m})$} \\
\cline { 2 - 5 } & $\mathbf{0 - 2}$ & $\mathbf{2 - 4}$ & $\mathbf{4 - 8}$ & $\mathbf{8 - 1 6}$ & $\mathbf{1 6 - 3 2}$ \\
\hline & & & g dm & \\
& & & $8,57 \mathrm{bC}$ & $7,33 \mathrm{bD}$ & $5,42 \mathrm{bE}$ \\
Testemunha & $12,17 \mathrm{bA}$ & $10,05 \mathrm{bB}$ & $9,69 \mathrm{aC}$ & $7,93 \mathrm{bD}$ & $6,90 \mathrm{aE}$ \\
Pangola & $13,01 \mathrm{aA}$ & $10,50 \mathrm{bB}$ & $10,53 \mathrm{aC}$ & $8,59 \mathrm{aD}$ & $6,45 \mathrm{aE}$ \\
Capim-elefante & $12,40 \mathrm{bA}$ & $11,66 \mathrm{aB}$ & $9,87 \mathrm{aC}$ & $9,24 \mathrm{aC}$ & $7,36 \mathrm{aD}$ \\
Siratro & $14,08 \mathrm{aA}$ & $10,87 \mathrm{aB}$ & $9,69 \mathrm{aC}$ & $6,70 \mathrm{aD}$
\end{tabular}

Médias de tratamentos acompanhadas pela mesma letra não diferem entre si pelo teste de Tukey a 1\%; as letras minúsculas comparam as amostragens de acordo com a profundidade (horizontal); as maiúsculas comparam as culturas (coluna).

Quadro 3. Teores de carbono orgânico total do solo (COT), considerando três posições de amostragem (superior, média e inferior), numa declividade de $12 \%$ - com a utilização de algumas culturas recuperadoras de áreas degradadas

\begin{tabular}{|c|c|c|c|}
\hline \multirow{2}{*}{ Tratamento } & \multicolumn{3}{|c|}{ Posição de amostragem } \\
\hline & Superior & Médio & Inferior \\
\hline & \multicolumn{3}{|c|}{ - COT, $\mathrm{g} \mathrm{dm}^{-3}$} \\
\hline Testemunha (sem vegetal) & $8,87 \mathrm{aB}$ & $8,37 \mathrm{bB}$ & $8,90 \mathrm{aB}$ \\
\hline Pangola (Digitaria decumbens L) & $9,78 \mathrm{abA}$ & $9,24 \mathrm{bA}$ & $9,80 \mathrm{aA}$ \\
\hline Capim-el efante (Pennisetum purpureum L.) & 9,74 aA & $10,00 \mathrm{aA}$ & 9,77 aA \\
\hline Siratro (Macroptilium atropurpureum L.) & $10,51 \mathrm{aA}$ & $9,48 \mathrm{bA}$ & 10,87 aA \\
\hline Guandu (Cajanus cajan L) & $9,57 \mathrm{abA}$ & $9,11 \mathrm{bA}$ & 10,72 aA \\
\hline
\end{tabular}

Médias de tratamentos acompanhadas pela mesma letra não diferem entre si pelo teste de Tukey a 1\%; as letras minúsculas comparam as amostragens em relação à declividade (horizontal); as maiúsculas comparam as culturas (coluna). 
matéria orgânica eas demais características do solo (Bayer \& Mielniczuk, 1997b). Por outrolado, sistemas demanejo sem revolvimento do sol o e com al ta adi ção de resíduos aumentam o COT do solo (Testa et al., 1992), além de promover o acúmulo de nutrientes nas camadas superficiais (Merten \& Mielniczuk, 1992). Em solos que não recebem aplicações de esterco ou outros materiais orgânicos, o carbono orgânico é adicionado por meio da degradação das raízes e dos resíduos vegetais que retornam ao solo anualmente (Merten \& Mielniczuk, 1992).

\section{Capacidade de troca de cátions efetiva e potencial (em pH 7,0) - CTC}

No quadro 4 encontram-se os valores de CTC efetiva e da CTC potencial (pH 7,0) do solo, obtidos de acordo com as profundidades e espécies utilizadas como recuperadoras da área analisada. Dos resultados, observou-se a interação entreas culturas sobre a CTC efetiva e potencial nas profundidades analisadas. A CTC efetiva apresentou maiores valores com a utilização do siratro, que, na média, apresentou $76,01 \mathrm{mmol}_{\mathrm{c}} \mathrm{dm}^{-3}$, enquanto com o capim-pangola, capim-el efante e o guandu foram de 69,71 - 69,88 - 70,40 $\mathrm{mmol}_{\mathrm{c}} \mathrm{dm}^{-3}$, respectivamente. Porém, todas espécies foram diferentes $(P<0,01)$ da testemunha. O mesmo aconteceu com relação à CTC potencial (pH 7,0).

Com relação às profundidades, as camadas superiores foram as mais representativas em relação à CTC efetiva e CTC potencial, apresentando, em média, na camada de $0-2 \mathrm{~cm} 80,06 \mathrm{mmol}_{\mathrm{C}} \mathrm{dm}^{-3}$, enquanto as camadas de 2-4, 4-8, 8-16 e 16-32 cm apresentaram 72,03, 67,00, 64,61 e63,77 $\mathrm{mmol}_{\mathrm{c}} \mathrm{dm}^{-3}$, respectivamente, diferenciando-se a $1 \%$. Segundo
Bayer \& Mielniczuk (1997a), de maneira geral, a variação nos teores de COT afeta a CTC em pH 7,0 e a CTC efetiva do solo.

Analisando os dados, percebeu-se que a CTC do sol o relacionou-se com o material orgânico deste solo, ou seja, a utilização de espécies que apresentam uma cobertura vegetal diferenciada e conseqüentemente depositam um material orgânico diferenciado nosolo, favoreceu a melhoria das características químicas do solo, como se pode observar pelos dados da CTC, quando comparadas aos da testemunha. Segundo Bayer \& Miel niczuk (1999), dentreas características químicas afetadas pela matéria orgânica, destacamse a disponibilidade de nutrientes para as culturas, a capacidade de troca de cátions ea complexação de elementos tóxicos e micronutrientes.

\section{Teores de matéria orgânica, $\mathrm{P}, \mathrm{K}, \mathrm{Ca}, \mathrm{Mg}$, $\mathrm{H}+\mathrm{Al}$ e pH do solo}

As características quími cas do solo, representadas por teores de matéria orgânica, $\mathrm{P}, \mathrm{K}, \mathrm{Ca}, \mathrm{Mg}, \mathrm{H}+\mathrm{Al}$ e pelo $\mathrm{pH}$, de maneira geral, foram influenciadas pelos tratamentos, cujos valores se encontram nos quadros 5, 6, 7, 8 e 9.

No quadro 5, encontram-se os val ores de potássio do solo obtidos com a utilização das diferentes espécies estudadas. Pelos dados, observa-se que houveinteração das profundidades eas culturas com relação ao potássio. Os teores de potássio foram superiores nas parcelas vegetadas em relação à parcela sem vegetação (testemunha), sendo estes teores maiores estatisticamente $(P<0,01)$ nas camadas mais superficiais, dependendo de cada tratamento (pangola, capim-elefante, siratro e

Quadro 4. CTC efetiva eCTC potencial (pH 7,0) do solo em cinco profundidades, considerando a utilização de culturas para recuperação de área degradada

\begin{tabular}{|c|c|c|c|c|c|}
\hline \multirow{2}{*}{ Espécie } & \multicolumn{5}{|c|}{ Profundidade $(\mathrm{cm})$} \\
\hline & $0-2$ & $2-4$ & 4-8 & 8-16 & $16-32$ \\
\hline & \multicolumn{5}{|c|}{ CTC efetiva, $\mathrm{mmol}_{\mathrm{c}} \mathrm{dm}^{-3}$} \\
\hline Testemunha & $66,00 \mathrm{aD}$ & $61,09 \mathrm{aB}$ & $60,46 \mathrm{aB}$ & $57,01 \mathrm{aB}$ & $62,80 \mathrm{aA}$ \\
\hline Pangola & 86,55 aAB & $72,69 \mathrm{bA}$ & 66,91 bcAB & $61,97 \mathrm{cB}$ & $60,41 \mathrm{cA}$ \\
\hline Capim-elefante & $76,76 \mathrm{aC}$ & $74,92 \mathrm{abA}$ & 68,51 abcAB & 66,10 bcAB & $63,12 \mathrm{cA}$ \\
\hline Siratro & 91,60 aA & 78,97 bA & 71,54 bcA & 71,63 bcA & $66,31 \mathrm{cA}$ \\
\hline \multirow[t]{2}{*}{ Guandu } & $79,40 \mathrm{aBC}$ & $72,41 \mathrm{abA}$ & $67,57 \mathrm{bAB}$ & $66,36 \mathrm{bAB}$ & $66,23 \mathrm{bA}$ \\
\hline & \multicolumn{5}{|c|}{ CTC potencial, $\mathrm{mmol}_{\mathrm{c}} \mathrm{dm}^{-3}$} \\
\hline Testemunha & $77,08 \mathrm{bC}$ & 85,21 aA & $77,10 \mathrm{bB}$ & $72,59 \mathrm{bB}$ & $74,89 \mathrm{bA}$ \\
\hline Pangola & $95,62 \mathrm{aAB}$ & $83,50 \mathrm{bA}$ & $81,39 \mathrm{bAB}$ & 77,37 bcAB & $73,15 \mathrm{CA}$ \\
\hline Capim-elefante & $86,82 \mathrm{aB}$ & 86,27 aA & 82,35 abAB & $80,87 \mathrm{abAB}$ & $74,86 \mathrm{bA}$ \\
\hline Siratro & 98,07 aA & 92,35 aA & 87,21 abA & $86,71 \mathrm{abA}$ & 76,94 bA \\
\hline Guandu & 91,16 aАB & $85,31 \mathrm{aA}$ & $81,23 \mathrm{abAB}$ & 79,28 bAB & $76,96 \mathrm{bA}$ \\
\hline
\end{tabular}

Médias de tratamentos acompanhadas pela mesma letra não diferem entre si pelo teste de Tukey a 1\%; as letras minúsculas comparam as profundidades (horizontal); as maiúsculas, as culturas (coluna). Testemunha - parcela sem cobertura vegetal. 
guandu), decrescendo com a profundidade. Fato também comprovado por Bayer \& Mielniczuk (1997a), ao encontrarem que os teores de potássio foraminfluenciados pel os preparos de sol o esistemas de culturas, apresentando o maior val or na camada superficial.

No quadro 6, observam-se os teores de potássio conforme a posição de amostragem nas parcelas. Verifica-se, que, na posição inferior, o valor diferiu em média daquel es da parte mediana e superior do declive: $98,5,77,53$ e $72,2 \mathrm{mg} \mathrm{dm}^{-3}$, respectivamente. Com os teores de matéria orgânica, pH, fósforo, cál cio, magnésio e hidrogênio + alumínio, considerando as culturas (Quadro 7), pôde-se perceber a recuperação da área de acordo com os tratamentos utilizados em relaçãoà testemunha. Verificou-seuma superioridade da presença de culturas em relação à testemunha nos teores de matéria orgânica e magnésio, que não diferiram em relação ao pH em água, fósforo, cálcio e hidrogênio + alumínio. Porém, os teores de pH,

Quadro 5. Teores de potássio em amostras do solo coletadas em cinco profundidades, considerando a utilização de espécies para recuperação de área degradada

\begin{tabular}{lccccc}
\hline \multirow{2}{*}{ E spécie } & \multicolumn{5}{c}{ Profundidade (cm) } \\
\cline { 2 - 6 } & $\mathbf{0 - 2}$ & $\mathbf{2 - 4}$ & $\mathbf{4 - 8}$ & $\mathbf{8 - 1 6}$ & $\mathbf{1 6 - 3 2}$ \\
\hline & & & Potássio $\left(\mathrm{mg} \mathrm{dm}^{-3}\right)$ \\
Testemunha & $95,0 \mathrm{aB}$ & $59,2 \mathrm{aB}$ & $73,3 \mathrm{aA}$ & $61,9 \mathrm{aA}$ & $48,1 \mathrm{aA}$ \\
Pangola & $203,9 \mathrm{aA}$ & $129,2 \mathrm{bA}$ & $69,4 \mathrm{bcA}$ & $29,7 \mathrm{cA}$ & $20,8 \mathrm{cA}$ \\
Capim-elefante & $152,2 \mathrm{aAB}$ & $161,4 \mathrm{aA}$ & $98,6 \mathrm{abA}$ & $40,3 \mathrm{bcA}$ & $23,6 \mathrm{cA}$ \\
Siratro & $171,7 \mathrm{aA}$ & $108,1 \mathrm{abAB}$ & $70,6 \mathrm{bcA}$ & $40,6 \mathrm{cA}$ & $18,6 \mathrm{cA}$ \\
Guandu & $141,9 \mathrm{aAB}$ & $109,2 \mathrm{abAB}$ & $73,0 \mathrm{bcA}$ & $45,3 \mathrm{bcA}$ & $22,8 \mathrm{cA}$
\end{tabular}

Médias de tratamentos acompanhadas pela mesma letra não diferem entre si pelo teste de Tukey a 1\%; as letras minúsculas comparam as profundidades (horizontal); as maiúsculas comparam as culturas (coluna). Testemunha - parcela sem cobertura vegetal .

Quadro 6. Teores de potássio, considerando a posição de amostragem (superior, média e inferior), em parcelas com declividade de $\mathbf{1 2} \%$ utilizadas com culturas na recuperação de áreas degradadas

\begin{tabular}{lccc}
\hline \multicolumn{1}{c}{ Tratamento } & \multicolumn{2}{c}{ Posição de amostragem } \\
\cline { 2 - 3 } & Superior & Médio & Inferior \\
\hline Testemunha (sem vegetal) & & Potássio $\left(\mathrm{mg} \mathrm{dm}^{-3}\right)$ & $80,30 \mathrm{aB}$ \\
Pangola (Digitaria decumbens L) & $56,67 \mathrm{aA}$ & $65,50 \mathrm{aA}$ & $102,17 \mathrm{aAB}$ \\
Capim-elefante (Pennisetum purpureum L.) & $83,00 \mathrm{aA}$ & $86,67 \mathrm{aA}$ & $138,17 \mathrm{aA}$ \\
Siratro (Macroptilium atropurpureum L.) & $49,67 \mathrm{bA}$ & $97,83 \mathrm{aA}$ & $87,67 \mathrm{aAB}$ \\
Guandu (Cajanus cajan L) & $85,00 \mathrm{aA}$ & $73,00 \mathrm{aA}$ & $84,17 \mathrm{aB}$
\end{tabular}

Médias de tratamentos acompanhadas pela mesma letra não diferem entre si pelo teste de Tukey a 5\%; as letras minúsculas comparam as amostragens com a declividade (horizontal); as maiúsculas comparam as culturas (coluna).

Quadro 7. Teores médios de matéria orgânica, pH em água, fósforo, cálcio, magnésio e hidrogênio + alumínio, considerando as gramíneas e leguminosas utilizadas para recuperar a área degradada

\begin{tabular}{|c|c|c|c|c|c|c|}
\hline Espécie & M.O. & pH em água & Fósforo & Cálcio & Magnésio & $\mathbf{H}+\mathbf{A l}$ \\
\hline & $\mathrm{g} \mathrm{dm}^{-3}$ & $(1: 2,5)$ & $\mathrm{mg} \mathrm{dm}^{-3}$ & 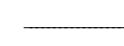 & $\mathrm{Cmol}_{\mathrm{c}} \mathrm{dm}^{-3}$ & - \\
\hline Testemunha & $15,0 \mathrm{~b}$ & $6,0 \mathrm{a}$ & $1,5 \mathrm{a}$ & $4,3 a$ & $1,6 \mathrm{c}$ & $1,4 \mathrm{a}$ \\
\hline Pangola & 16,6 a & $6,2 \mathrm{a}$ & $5,2 \mathrm{a}$ & $4,5 \mathrm{a}$ & $2,1 \mathrm{~b}$ & $1,2 \mathrm{a}$ \\
\hline Capim-elefante & $17,1 \mathrm{a}$ & $6,2 \mathrm{a}$ & $2,5 a$ & $4,3 a$ & $2,3 \mathrm{~b}$ & $1,2 \mathrm{a}$ \\
\hline Siratro & 17,8 a & $6,1 \mathrm{a}$ & $2,0 a$ & $4,1 \mathrm{a}$ & $3,2 \mathrm{a}$ & $1,2 \mathrm{a}$ \\
\hline Guandu & 17,0 a & $6,2 \mathrm{a}$ & $1,9 \mathrm{a}$ & $4,4 \mathrm{a}$ & $2,3 \mathrm{~b}$ & $1,2 \mathrm{a}$ \\
\hline
\end{tabular}

Médias de tratamentos acompanhadas pela mesma letra não diferem entre si pelo teste de Tukey a 5\% (coluna). 
matéria orgânica, fósforo, cálcio e magnésio (Quadro 8) foram superiores ( $P<0,01$ ) nas camadas superficiais, decrescendo em profundidade.

A avaliação do potencial químico de um solo, para fins de monitoramento da recuperação de áreas requer procedimentos diferenciados em relação às amostragens efetuadas para fins agrícol as, para não subestimar ou superestimar os teores de nutrientes no solo. Na utilização de amostragens com intervalos diferenciados de profundidade e declividade, observou-se mais precisamente a quantidade desses elementos no perfil do solo.

Pelos dados apresentados, observou-se uma diferença nos teores dos el ementos de acordo com a profundidade. Motta N eto (1996) informou que, na maioria das vezes, as análises efetuadas nas camadas superficiais podem subestimar ou superestimar esses valores.

No quadro 9, observou-se o maior teor dematéria orgânica na parteinferior da parcela, queapresentou $17,25 \mathrm{~g} \mathrm{dm}^{-3}$, enquanto, na parte média, esse valor caiu para $16,02 \mathrm{~g} \mathrm{dm}^{-3}$, sendo $16,72 \mathrm{~g} \mathrm{dm}^{-3}$ para a superior, provavelmente em conseqüência do arraste de solo e material orgânico da posição superior para a posição inferior. No entanto, o pH, fósforo, cálcio, magnésio e hidrogênio + alumínio não diferiram em relação a essas posições de col eta.
Neste trabalho, por não ter havido revolvimento nas camadas do solo, que provoca a eliminação da matéria orgânica na camada superficial (Mielke et al., 1986), verificou-se pelas análises efetuadas que as culturas mel horaram os teores de nutrientes no solo.

\section{CONCLUSÕES}

1. Nas condições experimentais, a utilização das leguminosas (feijão guandu - Cajanus cajan L. e siratro - Macroptilium atropurpureum L.) e das gramíneas (capim-pangola - Digitaria decumbens $L$. e capim-el efante - Pennisetum purpureum L.) promoveu aumento nos teores de carbono orgânico total e na capacidade de troca de cátions, indicando serem viáveis na recuperação de solos degradados. O siratro apresentou mel hor resposta em relação à CTC.

2. Os teores de $\mathrm{K}$ foram superiores nas parcelas vegetadas, quando comparados aos da testemunha, principalmente nas camadas superficiais, decrescendo com a profundidade.

3. Ocorreu um aumento nos teores de $\mathrm{MO}$ e Mg nas parcelas vegetadas quando comparados aos da

Quadro 8. Teores médios de matéria orgânica, fósforo, cálcio, magnésio, hidrogênio + alumínio e pH em água, considerando as profundidades do solo

\begin{tabular}{|c|c|c|c|c|c|c|}
\hline Profundidade & M.O & pH em água & Fósforo & Cálcio & Magnésio & $\mathbf{H}+\mathbf{A l}$ \\
\hline & $\mathrm{g} \mathrm{dm}^{-3}$ & $(1: 2,5)$ & $\mathrm{mg} \mathrm{dm}{ }^{-3}$ & 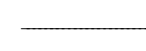 & $\mathrm{Cmol}_{\mathrm{C}} \mathrm{dm}^{-3}$ & - \\
\hline $0-2$ & $22,3 \mathrm{a}$ & $6,32 a b$ & $6,70 a$ & $4,64 a$ & $2,84 \mathrm{a}$ & $0,95 \mathrm{c}$ \\
\hline $2-4$ & 18,6 b & $6,43 a$ & $2,43 a b$ & $4,44 a b$ & $2,36 \mathrm{~b}$ & $1,25 \mathrm{~b}$ \\
\hline $4-8$ & $16,6 \mathrm{c}$ & $6,10 \mathrm{bc}$ & $1,43 \mathrm{~b}$ & $4,24 a b$ & $2,15 \mathrm{bc}$ & $1,49 \mathrm{a}$ \\
\hline $8-16$ & $14,4 d$ & $5,90 \mathrm{c}$ & $1,49 \mathrm{~b}$ & $4,06 \mathrm{~b}$ & 2,18 bc & $1,48 \mathrm{a}$ \\
\hline $16-32$ & $11,3 \mathrm{e}$ & $5,93 \mathrm{c}$ & $0,89 \mathrm{~b}$ & $4,29 a b$ & $1,92 \mathrm{c}$ & $1,16 \mathrm{bc}$ \\
\hline
\end{tabular}

Médias de tratamentos acompanhadas pela mesma letra não diferem entre si pelo teste de Tukey a 5\% (coluna).

Quadro 9. Teores médios de matéria orgânica, pH em água, fósforo, cálcio, magnésio e hidrogênio +alumínio, considerando a posição de amostragem em parcelas com 12\%de declividade (superior, média e inferior). Profundidade de 0-30 cm

\begin{tabular}{|c|c|c|c|c|c|c|}
\hline Posi ção de coleta & M.O & pH em água & Fósforo & Cálcio & Magnésio & $\mathbf{H}+\mathbf{A l}$ \\
\hline & $g \mathrm{dm}^{-3}$ & $(1: 2,5)$ & $\mathrm{mg} \mathrm{dm}^{-3}$ & 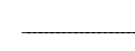 & $\mathrm{Cmol}_{\mathrm{c}} \mathrm{dm}^{-3}$ & - \\
\hline Superior & $16,72 a b$ & 6,14 a & $3,34 \mathrm{a}$ & $4,42 \mathrm{a}$ & $2,33 \mathrm{a}$ & $1,34 \mathrm{a}$ \\
\hline Mediana & $16,02 \mathrm{~b}$ & 6,12 a & $2,03 \mathrm{a}$ & $4,29 \mathrm{a}$ & $2,13 \mathrm{a}$ & $1,26 \mathrm{a}$ \\
\hline Inferior & $17,24 a$ & 6,16 a & $2,39 \mathrm{a}$ & $4,30 \mathrm{a}$ & $2,41 \mathrm{a}$ & $1,20 \mathrm{a}$ \\
\hline
\end{tabular}

Médias de tratamentos acompanhadas pela mesma letra não diferem entre si pelo teste de Tukey a $5 \%$ (coluna). 
testemunha. Já em relação à profundidade, houve um decréscimo nos teores de $\mathrm{MO}, \mathrm{Ca}, \mathrm{Mg}$ e $\mathrm{P}$, e não houve efeito nos teores de $\mathrm{P}, \mathrm{Ca}, \mathrm{Mg}$ e H +Al com relação às posições de col eta.

4. O acúmulo da manta vegetal sobre o solo (liteira) foi maior no tratamento com capim-elefante, sendo este acúmulo maior na posição inferior em todos os tratamentos.

\section{LITE RATURA CITADA}

BAYER, C. Dinâmica da matéria orgânica em sistema de manejo de solos. Porto Alegre, U niversidade Federal do Rio Grande do Sul, 1996. 240p. (Tese de Doutorado)

BAYER, C. \& MIELNICZUK, J. Nitrogênio total de um solo submetido a diferentes métodos de preparo e sistemas de cultura. R. Bras. Ci. Solo, 21:235-239, 1997a.

BAYER, C. \& MIELNICZUK, J . Características químicas do solo afetados por métodos de preparo e sistemas de cultura. R. Bras. Ci. Solo, 21:105-112, 1997b.

BAYER, C. \& MIELNICZUK, J. Dinâmica e função da matéria orgânica. In: SANTOS, G.A. \& CAMARGO, F.A.O., eds. Fundamentos da matéria orgânica do solo: ecossistemas tropicais e subtropicais. Genesis, Porto Alegre, 1999. p.9-26.

BERTONI,J .; PASTANA, F.I.; LOMBARDI NETO, F. \& BENATTI J r., R. Conclusões gerais das pesquisas sobre conservação do solo no Instituto Agronômico. Campinas, Instituto Agronômico de Campinas, 1972. 56p. (Circular, 20)

DALAL, R.C. \& MAYER, R.J . Long-term trends in fertility of soils under continuous cultivation and cereal cropping in Southern Queensland. I. Overall changes in soil properties and trends in winter cereal yiel ds. Aust. J . Soil Res., 24:265279, 1986a.

DALAL, R.C. \& MAYER, R.J . Long-term trends in fertility of soils under continuous cultivation and cereal cropping in Southern Queensland. II. Total organic carbon and its rate of from the soil profile. J. Soil Res., 24:281-292, 1986b.

DORAN, J.W. \& PARKIN,T.B. Defining and assessing soil quality. In: DORAN, J.W.; COLEMAN, D.C.; BEZDICEK, D.F. \& ETEWART, B.A., eds. Defining soil quality for a sustainable environment. Madison, Soil Science Society of American, 1994. p.3-21 (SSSA Special Publication, 35)
EMPRESA BRASILEIRA DE PESQUISA AGROPECUÁRIA EMBRAPA. Manual de métodos de análise de solo. 2.ed. Rio deJ aneiro, Centro Nacional de Pesquisa de Solos, 1997. 212p.

GONÇALVES, C.N. \& CERETA, C.A. Plantas de cobertura de solo antecedendo o milho e seu efeito sobre o carbono orgânico do solo, sob plantio direto. R. Bras. Ci. Solo, 23:307313, 1999.

LARSON, W.E. \& PIRCE, F.J . The dynamics of soil quality as measure of sustainable management. In: DORAM, J.W. et al., eds. Defining soil quality for sustainable environment. Madison, American Society of Agronomy, 1994. p.37-51.

$L A L, R . \& P I R C E, F . J$. The vanishing resource. In: LAL, R. \& PIRCE, F.J ., eds. Soil managemente for sustainability. Ankeny, Soil and Water Conservation Society, 1991. p.1-5.

MERTEN, G.H. \& MIELNICZUK, J. Distribuição do sistema radicular e dos nutrientes em latossolo roxo sob dois sistemas de preparo de solo. R. Bras. Ci. Solo, 15:369-374, 1992.

MIELKE, L.N.; DORAN, J.W. \& RICHARDS, K.A. Physical environment near the surface of plowed and no-tilled soils. Soil Till. Res., 7:355-366, 1986.

MIELNICZUK, J. Matéria orgânica e a sustentabilidade de sistemas Agrícolas. In: SANTOS, G.A. \& CAMARGO, F.A.O., eds. Fundamentos da matéria orgânica do sol o: ecossistemas tropicais e subtropicais. Genesis, Porto Alegre, 1999. p.1-8.

MIYASAKA, S. Histórico de estudos de adubação verde, leguminosas viáveis e suas características. In: FUNDAÇÃO CARGI L. Adubação verde no Brasil. Campinas, 1984. p.64124.

MOTTA NETO, J.A. Processos químicos e físicos na dinâmica de recuperação de solos degradados: uma visão interior. In: Recuperação de áreas degradadas - III Curso de Atualização. Curitiba, Universidade Federal do Paraná, 1996. p.129-133.

TESTA, V.M.; TEIXEIRA, L.A.J. \& MIELNICZUK, J. Características químicas de um PodzólicoVermel ho-E scuro afetadas por sistemas de cultura. R. Bras. Ci. Solo, 16:107114, 1992

WOODS, L.E \& \& SCHUMAN, G.E. Cultivation and slope position effects on soil organic matter. Soil Sci. Soc. Am. J., v.52, p.1371-1376, 1988. 
A.C. SANTOS et al.

R. Bras. Ci. Solo, 25:1063-1071, 2001 